\title{
A FALTA DE ÉPICA BUENAS SON LAS HISTORIAS. EL “HÉROE” EN LA NARRATIVA LATINOAMERICANA ACTUAL
}

\author{
POR \\ Claudio Maíz \\ Universidad Nacional de Cuyo
}

\section{EL HÉROE EN LOS ESTUDIOS LITERARIOS}

Los estudios sobre el héroe en la literatura latinoamericana más reciente no abundan. Uno de los mayores esfuerzos de conjunto que se hiciera data de los años 70 del siglo pasado, y fue Luis B. Eyzaguirre quien estudió el tema en su libro El Héroe en la novela hispanoamericana del siglo XX (1973). El libro es fruto además de una línea crítica que hoy ha caído en desuso y ha sido ampliamente superada. Nos referimos al método generacional con el que el crítico chileno trabajó. No es nuestro propósito ocuparnos de este estudio sino que nos interesa destacar la escasa atención que ha merecido el "héroe" después de este libro, a esta altura nada más que un punto de referencia. Sin embargo y a favor de Eyzaguirre se puede decir que el propósito general de su estudio consistió en poner de relieve, dentro del contexto social de su tiempo y por medio de la indagación del hombre en los mundos novelescos, "Los desvelos del novelista por sus criaturas". Esta preocupación de los creadores compartía una experiencia que no era solamente hispanoamericana, sino de la novela en general por entonces, Eyzaguirre escribe: "En la novela hoy, -escribe el crítico-así en Hispanoamérica como en el resto del mundo, se vive un momento en el que la visión trágica de los destinos del hombre tiene plena vigencia" (16). Para Eyzaguirre los protagonistas de la nueva novela hispanoamericana en pleno vigor por aquellos años estaban insertos en dicha atmósfera. La nueva novela llevaba a los "héroes novelescos" a situaciones extremas, quienes se veían compelidos a "echar mano a fuerzas que parecían inexistentes" para hallar las "defensas contra el desafío máximo" (17). Nos importa subrayar esta idea de la visión trágica de los destinos del hombre que atraviesa la nueva novela hispanoamericana, tanto como la de "fuerzas inexistentes" ante "máximos desafíos". De manera muy sintética lo dicho casi podría fungir como una fórmula de la épica misma. Con un sentido más moderno y bajo un especial compromiso social, uno de los escritores que con mayor énfasis defendió las posibilidades épicas de la novela hispanoamericana fue Alejo Carpentier: 
Pero esto no quiere decir que la novela, en general, esté en crisis. Está en crisis donde se la somete a los viejos módulos. Está viva, y bien viva, por el contrario, donde se convierte en novela épica, donde la posibilidad de ser épica la sustrae a la anécdota demasiado particular, donde su movimiento mismo le permite vivir en función de su época, expresando realidades que son las del tiempo en que vive el novelista, del tiempo que les es posible asir. ("Papel social del novelista" 161)

Ahora bien, las observaciones sobre la naturaleza del héroe de la nueva novela acompañan desde la serie literaria, en buena medida, la curva que se describe en el horizonte histórico-político que va de los años 1960-1970 a nuestros días. En otras palabras y en términos generales, la visión del hombre en la novela ya no es únicamente trágica (o épica en el sentido dado por Carpentier, según pudimos ver), como lo fuera durante la vigencia de la nueva novela, ${ }^{1}$ sino que las poéticas estallan en un haz muy variado de perspectivas (Shaw), en la que el héroe es despojado del aura sobrehumana precedente y recupera una escala estrictamente humana. Lo expresado se constata, panorámicamente, en la reescritura de la historia, uno de los mejores ejemplos: hay un Colón de Augusto Roa Bastos o de Alejo Carpentier, un Lope de Aguirre de Abel Posse u Otero Silva, un Magallanes de Baccino Ponce de León, todos personajes novelescos que se apropian del nombre histórico, sin ningún aura heroico. Por la misma senda, la narrativa humorística, la sentimental, la que incorpora los tópicos de la cultura masiva o todo ello junto: ahí tenemos las desventuras de los personajes de Alfredo Bryce Echenique, la incorporación de los íconos del cine en Manuel Puig o temas de tonos menores en Antonio Skármeta. Por lo dicho, para comprender la abundancia actual de tantos "perdedores" en la narrativa latinoamericana, hay que revisar antes la heroicidad que impregnó la narrativa del Boom. Puesto que, a nuestro entender, la conexión se hace ineludible para comprender los cambios rotundos en las poéticas narrativas actuales y el rechazo generado hacia aquéllas otras. Castellanos Moya, uno de los escritores que veremos más adelante expresa respecto del sentimiento generalizado de su promoción literaria: "Odiaban la llamada 'literatura de emergencia' que pregonaban Mario Benedett y sus epígonos". ${ }^{2}$ Pero no sólo eso hace falta, es decir actualizar la mirada sobre las poéticas, también es necesaria una revisión de los contextos en los que estos fenómenos de la novela de entonces y de ahora han tenido lugar.

Dicho sea de paso a esta altura la denominación "nueva novela" tiene una carga histórica tan marcada como la que tendría, por caso, la "novela de la tierra".

Sin embargo, escribe Castellanos Moya (Breves palabras impúdicas) los mismos poetas desencantados con la "literatura de emergencia", "no eran ajenos tampoco al hecho de que Conti había sido secuestrado y desaparecido por los militares argentinos dos años atrás." (15)

17everista Iberoamericana, Vol. LXXIX, Núms. 244-245, Julio-Diciembre 2013, 951-968 ISSN 0034-9631 (Impreso) ISSN 2154-4794 (Electrónico)

\section{LA "GUERRA FRÍA CULTURAL"}

Es conveniente para nuestros fines describir el contexto de la narrativa hispanoamericana que logró imponerse internacionalmente hacia los años 1960 y 1970 Esta producción literaria se desarrolla durante la Guerra Fría, un fenómeno geopolítico que tuvo su comienzo en América Latina con la Revolución cubana y un preludio en la intervención norteamericana de 1954 en Guatemala ${ }^{3}$ Como lo demuestran las numerosas polémicas que se entablan entre escritores, críticos literarios, periodistas culturales Cortázar/Arguedas; Rama/Rodríguez Monegal, son apenas unas muestras-, los campos de la política y de la cultura se estrechan, en ciertos casos hasta la fusión. Entre muchos, uno de los tantos centros del debate en el espacio literario se ubica en la conversión del escritor "burgués" en un intelectual comprometido. El papel pedagógico del escritor es redefinido, si se lo piensa con relación a la novela anterior, la de las primeras décadas del siglo xx (Naturalismo, Mundonovismo, etc.). Para Jean Franco, ahora el escritor se erige como un guía de la lectura, puesto que introduce teorías, textos críticos que influyen sobre la manera de cómo debían ser leídas sus obras, cómo podía entenderse la historia y qué valorización debía dársele al lenguaje. ${ }^{4}$ Pero no limitaron su influencia al campo cultural de la época sino que también llegaron a ocupar el lugar de mentores en sustitución de los políticos (14). Asumen, pues, un liderazgo moral. Esta posibilidad se materializa gracias a la relación existente entre "cambios sociales" y "narrativas de la identidad". ${ }^{5}$ No obstante, todas estas condiciones favorables que convertían al escritor

"Las Revoluciones cubana y nicaragüense parecieron surgir naturalmente de sus respectivos pasados y nacionales y apelaron al siempre vigente programa de liberación nacional que permitiría a los países latinoamericanos desarrollar su propio estilo de modernización en territorios liberados, sin la mácula de la corrupción y el materialismo del pasado" (Franco, Decadencia y caida de la ciudad letrada 11). Para el tema de la conexión entre política y cultura durante la Guerra Fría, véase también Stonor Sauders, Benedetta.

Los casos más notables son los de Jorge Luis Borges, Carlos Fuentes, Octavio Paz, Lezama Lima, Julio Cortázar, José María Arguedas, entre otros (13) Franco (2003). Véase asimismo: Franco, Jean (1981). En este texto, Franco explicita su idea de heroicidad del autor: "No nos sorprende, entonces, que la noción del autor como héroe cultural [...] viene a ser vista como una especie de salvación del anacronismo. No me refiero solamente al concepto restringido del autor dada por Foucault cuando habla de "la persona a quien se le puede atribuir legítimamente la producción de wn texto, libro u obra", sino ta person

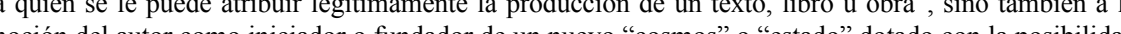

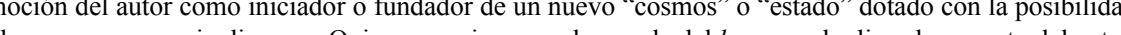
de generar su propio discurso. Quiero sugerir que en la novela del boom se duplica el concepto del autor ya que no sólo designa al escritor de una novela, sino a la novela misma funcionando como modelo sobre el cual se refleja el proyecto utópico de la formación de una nueva sociedad en los márgenes de la vieja" (131-132). Es interesante como muestra de la preocupación crítica de los novelistas, la antología de Wilfredo Corral y Norma Klan (1991).

Estos desplazamientos se detectan también en el ámbito de la crítica literaria. "Los intelectuales de la literatura" son aquellos que abandonan la específica labor limitada a la interpretación de textos literarios para desplazarse a la dimension pública. Entre las nuevas labores está la de interpelar los lugares comunes

17. Revista Iberoamericana, Vol. LXXIX, Núms. 244-245, Julio-Diciembre 2013, 951-968 ISSN 0034-9631 (Impreso) $\quad$ ISSN 2154-4794 (Electrónico) 
en un actor de la vida pública cuya palabra era altamente valorada, nada podía superar, como dice Franco "la idealizada austeridad del guerrillero y la idealizada sencillez del campesino". Ambos alumbramientos "[...] no eran compatibles con la exuberancia y el exceso de la estética, ni con el estatus del escritor como héroe" (12). A pesar de todo, la historia de América Latina encontró en la poesía, curiosamente no en la novela realista, la organización de su relato fragmentado, claro está que "como una aventura épica" acorde a los tonos idealistas del momento (13). En resumen, el escritor como "héroe" y la historia como "aventura épica" son otros dos componentes que sumados a "los máximos desafíos" a los que los personajes de la nueva novela son sometidos en el contexto de la "guerra fría cultural" completan someramente el cuadro que nos interesa describir, a fin de indagar los bruscos contrastes con la narrativa contemporánea.

Dijimos anteriormente que el marco más vasto en el que debía delinearse el proceso de cambios tan nítidos fue la Guerra Fría, es decir, lo que historiadores y teóricos políticos definen como el producto de un mundo bipolar, que emergió luego de los Acuerdos de Yalta al finalizar la Segunda Guerra Mundial. Ahora bien, la supuesta "frialdad" de tal guerra entre el mundo capitalista, con Estados Unidos a la cabeza y el comunismo soviético no fue más que un eufemismo, ya que los conflictos bélicos fueron numerosos y cruentos, aunque focalizados en áreas específicas y calientes (Corea, Vietnam, los liberados países africanos). EnAmérica Latina la “guerra fría” también fue una expresión eufemística, ya que en Centroamérica y el Caribe la intervención norteamericana fue directa y en el Cono Sur, la "guerra fría" se tornó "guerra sucia" (Chile, Argentina, Uruguay, Paraguay, Brasil mismo). Estas circunstancias políticas vividas en las décadas indicadas ponen fin al llamado "proyecto republicano de la Ilustración", como lo dice Jean Franco (Decadencia y caída de la ciudad letrada 22). La expresión entendida como un propósito compartido por las naciones latinoamericanas, en las que las ciudades asumían un papel crucial en tanto agentes impulsores de la civilización y el progreso, no era más que una apariencia que encubría desde la Ilustración misma en adelante la irrealización republicana. ${ }^{6} \mathrm{Al}$ haberse aceptado esta imagen de América, cuando

del imaginario social y el poder. De esta manera los define Gonzalo Aguilar ("Los intelectuales de la literatura: cambio social y narrativas de identidad") en su estudio sobre la relación entre el cambio social y narrativas de identidad. Antonio Candido, Ángel Rama, Antonio Cornejo Polar, Ana Pizarro son algunos le los representantes de la transforión Ar An Thoya alidad del escritor, su herencia y el cruce de las fronteras nacionales.

François Xavier Guerra (Annino, Guerra Inventando la nación) ha planteado que la aparición de las nuevas "naciones" en Iberoamérica no está precedida por movimientos nacionalistas, sino que es et resultado de la desintegración de dos construcciones políticas: la monarquía hispánica y el imperio luso-brasileño. (9) Agrega: "La construcción de la nación requería de mitos compartidos por todos: una historia de la génesis de la nación, de sus héroes fundadores y de sus enemigos, del horrible pasado del que ha logrado liberarse y del grandioso futuro que le cabe esperar [...]". Más adelante: "La fe en la constitución, característica del siglo xIX es, a la vez, fundamento y proyecto de la nueva sociedad" (11).

17.7 Revista Iberoamericana, Vol. LXXIX, Núms. 244-245, Julio-Diciembre 2013, 951-968 ISSN 0034-9631 (Impreso) ISSN 2154-4794 (Electrónico) sobrevino el cambio brutal de las dictaduras de los 1970-1980, la utopía de suponer que la literatura y el arte poseían una especial cualidad redentora tocó su fin y con ello quizás el cierre de un ciclo.

\section{3. ÉPICA Y MODERNIDAD}

De manera que ya no hay lugar para la épica porque ya no existen los héroes. $\mathrm{Al}$ menos como los que se gestaron durante cierto periodo de la historia americana. Hay un sugerente ensayo de Germán Arciniegas titulado "El siglo XIX en América y la deshumanización del héroe", en el que sostiene que la deshumanización de los grandes conductores tiene lugar a través de un proceso que los convierte en mitos populares. Convenimos con él que "[...] nuestra tradición historiográfica ha sido constante en el propósito de deshumanizar a los héroes" (362). Además sostiene que tal "transmutación de los hombres en sustancia divina" no constituye solamente un fenómeno literario (362). Es un procedimiento más complejo mediante el cual los héroes pasan a ocupar el sitial de padres de la patria. El ensayista pone en dudas que la patria no existiera antes de la instauración de los héroes. En otras palabras, para que hubiera nacionalidad la existencia o no de héroes no era imprescindible, puesto que las ideas independentistas ya anidaban en la imaginación de los pueblos (365). ¿Dónde habita el costado extraordinario de aquellos hombres con atributos heroicos?: en "la capacidad de descubrir los sentimientos ocultos del pueblo" (365). La pregunta que queda en suspenso es si es posible la nacionalidad sin una patrística mítica, deshumanizada en el sentido que le da Arciniegas. La respuesta no parece ser otra que existe la nación en tanto y en cuanto es narrada de acuerdo con principios constructivos provenientes de la épica.

Ahora bien, decir que no hay épica porque no hay héroes parece una afirmación muy tajante, irreductible hasta en cierto modo, extemporánea si pensamos lo dicho desde una de las perspectivas más obvias, es decir, la epocal, habida cuenta que la épica es un género del pasado. Dicho de otro modo, los estudios sobre el género épico tienen un sentido estrictamente histórico, incapaz de interpelarnos en el presente en tanto género mismo realizable, salvo que nos orientemos a otros lenguajes, como el cinematográfico. Sin lugar para la épica, es decir, para los relatos que ensalzan figuras tan triunfantes como grandiosas, la literatura le ha cedido desde hace tiempo la producción del relato épico a la cinematografía. ${ }^{7}$ En efecto, el cine ha sido el verdadero realizador de una épica que resultaría candorosa -se podría decir- en la literatura. Nuestra inquietud, sin embargo, intenta iluminar otra zona, retomando el curso de la narrativa actual hispanoamericana, esto es, cuál es la incidencia de los acontecimientos histórico-políticos posteriores a la

La guerra de las galaxias, El señor de los anillos, las Crónicas de Narnia, recogen y resignifican en sus sagas, con variados matices, las situaciones del mito del héroe, así como lo hace Harry Potter, héroe infantil y juvenil.

20vista Iberoamericana, Vol. LXXIX, Núms. 244-245, Julio-Diciembre 2013, 951-968 \begin{tabular}{ll}
\hline \hline ISSN 0034-9631 (Impreso) & ISSN 2154-4794 (Electrónico)
\end{tabular} 
década de 1970 que produjeron el fin del ideal de la vida, articulada al devenir de una épica de transformación social. Con tales antecedentes, la verosimilitud de personajes que triunfan no resulta nada sencillo en la narrativa actual latinoamericana. Para decirlo de una vez, el proceso de mutación del héroe es concomitante al eclipse de determinadas utopías. Y ésta es la segunda aseveración que intentamos desarrollar. El desencanto, el sentimiento de la derrota, el cinismo o la resistencia son algunas de las nuevas envestiduras que adquiere el personaje en las novelas actuales.

Ahora bien, la respuesta al interrogante de por qué hay historias, entendidas como diégesis signadas por la lectura y no epopeyas signadas por la oralidad fue respondida hace tiempo de diversas maneras: Mijail Bajtín, Arnold Hauser, desde la crítica y la historia literaria o Hegel desde la filosofía; el caso de Gyórgy Luckacs, quien también se ocupó del tema, se ubica en otro extremo en razón de que asume el papel de gran defensor de la épica frente a la tragedia, no debe olvidarse su estrecha adhesión al realismo socialista. Aunque las respuestas no coincidan, el tono general es que la epopeya es un género acabado, perimido. La heroicidad tal y como la conoció la antigüedad quedó desarticulada por la Modernidad. La epopeya dice Bajtín (Teoría y estética de la novela) al igual que otros géneros "son más antiguos que la escritura y el libro" (449), llevan las huellas de la oralidad y la sonoridad, la novela en cambio es el único género más joven (a lo que habría que agregar también el ensayo). He ahí un punto muy importante para nuestra argumentación. Si como se sostiene, la Modernidad incorporó la conciencia irónica en el surgimiento de la novela en un personaje como el Quijote, no hay heroicidad porque la conciencia se ha escindido, desdoblado, en suma, se ha tornado irónica. Una conciencia tal es incapaz de asumir el triunfo o el éxito como algo verosímilmente digno. Aún más, y en otro orden, el mundo bipolar también insidio aunque de manera oblicua sobre las ideas acerca de la épica y su supervivencia: por un lado el temprano optimismo socialista de Lukács habrá de encontrar el contrapeso hacia finales del siglo xx en el pesimismo posmodernista de Jean-Francois Lyotard expresado en su tratado La condición posmoderna donde declara que la "crisis de los grandes relatos" se identificaba con la crisis de los relatos modernos (Pedrosa 2005).

\subsection{La épica hispanoamericana}

No queremos alejarnos más de lo debido del tema que nos preocupa, es decir pensar el ocaso del héroe en la narrativa latinoamericana más reciente. A fin de ir acercándonos a nuestro punto queremos aludir brevemente a un ensayo de Carlos Fuentes, "Mariano Azuela: la "Ilíada" descalza". El escritor mexicano sigue los pasos de Ortega, Hegel, Bajtín en el análisis de la épica, de ahí que admita la épica como algo completo y la novela como algo incompleto, o en términos de Bajtín (Teoría y estética de la novela) la novela "[...] expresa mejor que otros géneros las tendencias de la evolución del mundo" (453). La novela sintéticamente-sigue ahora Bajtín, pero en la misma tesitura el propio Fuentes-, está distinguida por la novedad y la "[...] non correspondencia del héroe con su destino y su situación" (481). En la lectura que Carlos Fuentes (Valiente Mundo Nuevo) hace de Hegel, el mexicano destaca que la épica constituye un acto en el que el hombre se sacude el mito, es decir de su identificación de los dioses como actores, para asumir él mismo la acción. La épica en ese sentido sería una ruptura de una unidad simple, abriendo así el mundo pluralista de los poderes naturales y las fuerzas morales. Por eso el conflicto trágico no es de virtudes (lucha entre buenos y malos) sino de valores en el que ambas partes tienen razón. Fuentes afirma que la obra de Bernal Díaz del Castillo abre una curva histórica con una "épica vacilante", siendo la fuente secreta de la novela hispanoamericana (180), se continúa con la "épica degradada" de Mariano Azuela (181) y-agregamos nosotros- se cierra con la "épica fundadora" de los escritores del boom. Entre ambos extremos la "nación aspira a ser narración" y Azuela como ningún otro narrador de la Revolución Mexicana levanta "la pesada piedra de la historia para mirar lo que hay debajo y lo que encuentra es la historia de la colonia que hasta entonces no había sido narrada" (182). La novela como narración de la nación por tanto la novela como camino de la identidad. Este parece ser el corolario de Fuentes, que aporta a nuestra argumentación un nexo más entre la irrealización republicana de la nación, el fin de la utopía y la declinación del héroe.

Si la Modernidad se interpone entre la épica y la novela, el sentido último de esta transformación está refrendado por el reconocimiento de la derrota, del fracaso ya que en ello radica la única posibilidad para la esperanza. Es la relación que establece María Zambrano ("El sentido de la derrota") cuando afirma que la derrota "[...] es creadora en la historia como el fracaso individual lo es en el pensamiento, en el arte más perenne" (43).

$\mathrm{Si}$ se conviene en trazar conexiones (no determinantes) entre algunos cambios sociales y las narrativas de identidad de los escritores, estaríamos acercándonos a las posibles razones de por qué a falta de "épicas" mejor son las "historias". Con ello no sugerimos una lectura de determinadas novelas desde la perspectiva posdictatorial, que incluye la ficción, pero también la non-fiction o el testimonio. Las novelas que nos interesan pertenecen a otra "familia", en las que las historias han desmantelado la intangibilidad del héroe (en tanto autor o personaje) de los años 60 y 70 del siglo $\mathrm{xx}$, y en su lugar -dicho en términos generales- aflora una narrativa orientada a la incorporación de la figura del derrotado, del antihéroe, del que no aspira desafiar su destino y si lo hace no lo hará con aquellos recursos que probaron ser conducentes al fracaso. Los episodios traumáticos de las dictaduras del Cono Sur o las guerras civiles en Centroamérica encuentran en estas narrativas una manera loable de asumir el fracaso.
Revista Iberoamericana, Vol. LXXIX, Núms. 244-245, Julio-Diciembre 2013, 951-968 ISSN 0034-9631 (Impreso) 


\section{Perdedores en la ACCión, Ganadores en la CONSIDERACión}

¿Qué es un perdedor? ¿Cuáles son las condiciones que lo definen? Hans Magnus Enzensberger (El perdedor radical) distinguió los siguientes grados de la derrota: 1. el fracasado, quien se resigna a su suerte y claudica; 2 . la víctima que reclama satisfacción 3. el derrotado que se prepara para una nueva oportunidad; 4. el perdedor radical, quien se aparta del resto "se vuelve invisible, cuida su quimera, concentra sus energías y espera su hora" (6). La dignidad del perdedor que señalan desde Jorge Luis Borges a María Zambrano no es una condición unívoca e irrevocable. "El sacrificio es, a veces, más humano y más bello que el triunfo" (291), dice uno de los personajes de la novela La doble vida de Arturo Fontaine. También están los perdedores que por alguna razón descienden hasta la abyección. ${ }^{8}$

Ana María Amar Sánchez (Instrucciones para la derrota) ${ }^{9}$ ha registrado más de ochenta novelas en su mayoría publicadas no más allá de los años 1980 en lengua hispana que reúnen las características de un relato en las que el perdedor se reivindica conforme a una ética que lo pone por encima de sus adversarios ganadores:

Perder resulta así una forma de triunfo que ubica a los protagonistas más allá de sistema y les proporciona otra clase de éxito. Ser antihéroe perdedor, forma parte de los derrotados y garantiza pertenecer a un grupo superior de triunfadores: el de los que han resistido y fundan su victoria en la orgullosa aceptación de la derrota. (25)

La distinción entre "derrotado" y "fracasado" es crucial para que exista la compensación ante la derrota. El fracaso equivale a la "no realización" y ausencia tota de anclaje político, en fin, a la "no realización" (75). En cambio el "perdedor" es la figura que resiste la adversidad y hace de su vida una negativa al pacto o la integración (40). Los sentidos que predominan no son los de la melancolía sino los de la nostalgia (78) Escribir la historia de los derrotados no es un ejercicio autoflagelante sino una manera de construir una "metáfora de la historia" (14). ¿Poseen una dosis de resarcimiento? Probablemente, ya que ofrece soluciones imaginarias a la pregunta de cómo sobrevivir entre los ganadores y elaborar el trauma de la derrota (Freud Duelo y melancolía), pero también las metáforas que representan estos relatos recoge los significados de energías vacías, carentes de sentidos, que fueron puestas en objetivos que, aún aquéllos que

En la novela La vida doble de Arturo Fontaine (2010), que transcurre en Chile y en tiempos de la guerrilla, En la novela La vida doble de Arturo Fo El libro de An Má Anr Ś́ El ib reco a f de cre que recoge al fin de acnas sic de los grandes inherente a la derrota. Nuestras reflexiones se motivan en este exhaustivo trabajo de investigación. ISSN 0034-9631 (Impreso)

Vol. LXXIX, Núms. 244-245, Julio-Diciembre 2013, 951-968 ISSN 2154-4794 (Electrónico) parecieron triunfantes no son sino una máscara que oculta la corrupción, el privilegio, el abandono de los ideales.

\subsection{El perdedor nato}

Nos llevaría por otros senderos, pero el resurgimiento de la novela policial en Hispanoamérica (véase Anales de Literatura Hispanoamericana 2007; Lingüistica y Literatura 2009, Revista Iberoamericana 2010) obedece en gran medida a los efectos que la narrativa negra norteamericana había logrado en su cometido por desmontar los mitos del estilo de vida norteamericano surgidos de la sociedad industrial capitalista. La utilización de algunas de aquellas estrategias del policial norteamericano no se produce sino mediante una renovación tanto de los tópicos conocidos como de los fines perseguidos por el género. A tal punto es la innovación que se habla de una nueva novela policial o neopolicial en la que la mirada desencantada del investigador deja filtrar la realidad ambigua, caótica, diversa donde los buenos y malos no tienen roles fijos y preestablecidos. Como medio narrativo la corriente del neopolicial ha permitido escudriñar las madejas del Estado, sus vericuetos ocultos y peligrosos. Un Estado que ya no representa debidamente a la sociedad ni tampoco se deposita en él la fe en el uso adecuado y privativo de la fuerza, potestad que lo definía. Por el contrario, es al Estado y sus aparatos lo que verdaderamente enfrenta un conjunto de personajes detectivescos, cuya fortaleza no está en la razón sino principalmente en la desconfianza. Quizás la gran novedad provenga de que "el policial se convierte en un tipo de narración más realista, más psicológica y, sobre todo, más periodística". ${ }^{10}$

Mario Conde, el personaje de la saga de Leonardo Padura reúne en buena medida los caracteres señalados, pero su condición de perdedor acentúa su inserción en la maraña de la Historia (Amar Sánchez 19). Varias de las novelas de Padura se asientan el modelo

\footnotetext{
${ }^{10}$ Como lo hemos indicado y en coincidencia con Àlex Martín Escribá y Javier Sánchez Zapatero: "Las décadas de los setenta y ochenta se caracterizarán por el surgimiento de sangrientas dictaduras y por la sucesión de guerras civiles y diversos conflictos armados, con el consiguiente reflejo literario que esto conlleva". Agrega la autora: "Como referente, cabe citar el ejemplo cultivado por Manue Vázquez Montalbán -autor venerado en prácticamente toda Latinoamérica, además de en los ámbitos mediterráneos-, que en España y tras la muerte del dictador Franco en 1975, abre un camino que va a ser continuado ideológicamente por muchos autores posteriores en distintos países latinoamericanos. El creador de Pepe Carvalho supo mezclar de manera magistral la novela policíaca española con los acontecimientos políticos que iban sucediéndose durante la transición democrática y los cambios que esto comportó. La creación de un personaje desencantado y pintoresco como Carvalho permitio trazar un largo itinerario - a partir de Yo maté a Kennedy (1972) o más concretamente a partir de Tatuaje (1974) donde una dictadura de casi cuarenta años hasta una verdadera revolución post-industrial" (52).
} 
en el que el Teniente Mario Conde padece las nostalgias de las utopías desvanecidas. ${ }^{11}$ Sin embargo, en esta oportunidad queremos destacar otra novela que sale de ese modelo y se orienta en otra dirección, sin abandonar el interés por los "perdedores". Nos referimos a El hombre que amaba a los perros (2010), una extensa novela que relata el encuentro entre un solitario personaje, Iván, recientemente enviudado y otro que pasea unos galgos rusos en una playa cubana. Esta relación dispara varias historias paralelas pero que se engarzan a través de un singular episodio: el asesinato de León Trostsky en Coyoacán, aunque nada más que como una gran metáfora del fracaso no solamente del personaje "perdedor" por antonomasia como lo fue el revolucionario ruso sino de toda una generación. Iván convertirá en relato todos estos episodios hasta su muerte. El lector final de estos manuscritos dirá con furia que su amigo merecía la compasión:

[...] como todas las trágicas criaturas cuyos destinos están dirigidos por fuerzas superiores que los desbordan y los manipulan hasta hacerlos mierda. Ese ha sido nuestro sino colectivo, y al carajo Trotsky si con su fanatismo de obcecado y su complejo de ser histórico no creía que existieran las tragedias personales sino solos los cambios de etapas y suprahumanas. ¿Y las personas, qué? ¿Alguno de ellos pensó alguna vez en las personas? ¿Me preguntaron a mí, le preguntaron a Iván, si estábamos conformes con posponer sueños, vida y todo lo demás hasta que se esfumaran (sueños, vida y hasta el copón bendito) en el cansancio histórico y en la utopía pervertida? (570)

El hombre de los galgos rusos era Ramón Mercader, que luego de purgar su condena en México por el asesinato de Trotsky vivió en Cuba y terminó sus años en la URSS condecorado como héroe nacional. Las fuerzas superiores de la Historia, así como las supuestas leyes científicas que la rigen, quizás la mayor utopía científica del siglo xx, cede el lugar al individuo, a la incertidumbre, a los destinos azarosos.

\subsection{El perdedor cínicamente indignado}

Dos casos más e intentaremos una conclusión. Si por un lado los relatos son metáforas de la historia, por otro, son el recurso para la desmemoria y una tenue esperanza. Esta última vía pareciera ser la que nos propone Horacio Castellanos Moya (nacido en Tegucigalpa, pero afincado en El Salvador, 1957) cuando construye en El asco quizás uno de los relatos paradigmáticos del rechazo a un determinado status quo. El título completo de esta novela ${ }^{12}$ corta es El asco. Thomas Bernhard en San Salvador Se estructura mediante la representación de un diálogo que dura dos horas, si bien hay

\footnotetext{
${ }^{11}$ A través de su tetralogía "Las cuatro estaciones": Pasado perfecto (1991), Vientos de cuaresma (1994), Máscaras (1996) y Paisaje de otoño (1998). Véase: Franken K, Clemens A., (2009).

12 A decir verdad el texto está construido de acuerdo a una importante hibridez genérica, ya que se mezcla la crónica, la diatriba, la historia política.
}

174 Revista Iberoamericana, Vol. LXXIX, Núms. 244-245, Julio-Diciembre 2013, 951-968 ISSN 0034-9631 (Impreso) ISSN 2154-4794 (Electrónico) un interlocutor el relato fluye nada más que en la voz del personaje Edgardo Vega. Quien escucha es Moya, a la sazón el segundo apellido del autor, lo que hace pensar en un alter ego. ${ }^{13}$ Es probablemente una de las diatribas más feroces contra la nación, el nacionalismo y la Identidad, a tal extremo que puede considerarse como una novela de desembozado tono antinacional, con las graves consecuencias que ello conlleva: “[...]cómo pueden llamar 'nación' a un sitio poblado por individuos a los que no les interesa tener historia ni saber nada de su historia, un sitio poblado de individuos cuyo único interés es imitar a los militares y ser administradores de empresas [...]" (30). ${ }^{14}$ Brotan del monólogo rechazos cargados de furia contra la guerra civil que dejó "los cien mil muertos" nada más que como un "recurso macabro para que un grupo de políticos ambiciosos se repartiera un pastel de excrementos" (30). No hay indulgencia para la derecha ni para la izquierda política:

Y lo peor son esos miserables políticos de izquierda, Moya, esos que antes fueron guerrilleros, esos que antes se hacían llamar comandantes, ésos son los que más asco me producen, nunca creí que hubiera tipos tan farsantes, tan rastreros, tan viles, una verdadera asquerosidad de sujetos, luego que mandaron al sacrificio a tanto ingenuo, luego que se cansaron de repetir esas estupideces que llamaban sus ideales, ahora se comportan como las ratas más voraces, unas ratas que cambiaron el uniforme militar del guerrillero por el saco y la corbata, unas ratas que cambiaron sus arengas de justicia por cualquier migaja que cae de la mesa de los ricos, unas ratas que lo único que siempre quisieron fue apoderarse del Estado para saquearlo [...] (33)

Nos permitimos esta cita in extenso para trasmitir el tono beligerante, incontenible despiadado con el que aborda este como otros asuntos relevantes de la vida político-social

${ }_{13}$ Confiesa el autor en un ensayo (Breves palabras impúdicas): “A finales de 1978, no me cabía la menor duda de que mis compañeros de generación, poetas o no, iban con ritmo precipitado hacia la militancia revolucionaria; comprendí también que no había más opciones: tomar partido o largarse. Yo decid largarme. Apelé a mi abuela materna hondureña, una mediana terrateniente, y conseguí los fondos para irme a estudiar a Toronto en febrero de 1979" (16-17).

${ }_{14}$ Josefina Ludmer incluye la novela $E l$ asco de Castellanos Moya en un corpus de los años noventa del siglo pasado que en cierto modo denuncian el proceso de desnacionalziaciones y privatizaciones que caracterizó a esa década en la mayor parte de América Latina. Ludmer (2005) Para nosotros, sin embargo, 1 merado tono aninciont de esta novela sobrevien do los anto as huellas indelebles de la crun as huellas indelebles de la cridad con la que se libro. Es pate de la novela, no de la violencia, sino violenta, la disthiocón aunque sutil sive para desbrozar eategorzacions anteriores. Respecto de su novel El arma en el hombre (2008), Castellanos Moya ("El cadáver es el mensaje. Apuntes sobre literatura y violencia") comenta: "Yo no era, por supuesto, una golondrina haciendo verano. Mi libro formaba parte de una corriente literaria que en esa misma época florecía en Colombia, México y Brasil: la novela del sicario, del ex policía convertido en asesino a sueldo, del excombatiente reciclado en mercenario, del pistolero narcotraficante. Algunas novelas de Fernando Vallejo y de Jorge Franco en Colombia, las ficciones de Élmer Mendoza en México, y la obra de Rubén Fonseca en Brasil son excelentes muestras de esta expresión extrema de la cultura de la violencia en las ciudades latinoamericanas” (57).

14. Revista Iberoamericana, Vol. LXXIX, Núms. 244-245, Julio-Diciembre 2013, 951-968 ISSN 0034-9631 (Impreso) 
salvadoreña. Mientras se despacha con sus improperios, Vega escucha el Concierto en Si Bemol Menor para piano y orquesta de Tchaikovski y bebe whisky con su amigo Moya Si está en El Salvador es nada más porque ha fallecido su madre. Ha debido viajar desde Montreal, donde reside permanentemente desde hace dieciocho años y ha obtenido la ciudadanía canadiense. El grado de despojamiento de su identidad salvadoreña y por añadidura latinoamericana ("Conozco muy bien a esos farsantes dedicados a lucrar con las causas justas a través de la detestable y llorona música folclórica latinoamericana") llega al punto de cambiar su nombre: su pasaporte canadiense lo identifica como Thomas Bernhard, apenas un velado homenaje al escritor europeo de furiosas invectivas. ${ }^{15} \mathrm{La}$ cuota de cinismo se potencia con la escéptica opinión que tiene de su amigo:

Hay que estar, definitivamente, loco como vos, Moya, para creer que se puede cambia algo en este país, para creer que vale la pena cambiar algo, para creer que la gente le interesa cambiar algo, me dijo Vega, ni siquiera once años de guerra civil sirvieron para cambiar algo, once años de matanzas y quedaron los mismos ricos, los mismos políticos, el mismo pueblojodido y la misma imbecilidad permeando el ambiente. (62-63)

Es notable la cercanía que se percibe entre esta novela y su ensayo "La guerra un largo paréntesis" (2010). El desprecio a todo posible cambio que Vega le espeta a Moya es desde luego extremadamente pesimista, pero que expresa también el desencantado generalizado de la generación posterior al boom en el que abundan las críticas a Cuba, al castrismo, al culto a la muerte en pos del cambio, tampoco faltan las acusaciones por la muerte de Roque Dalton -el poeta salvadoreño- en manos de sus compañeros revolucionarios bajo la acusación de agente de la CIA. Escribe Castellanos Moya en el ensayo mencionado:

Ciertamente la generación literaria que nos precedió hizo del "compromiso" el eje de su vida y tuvo en la revolución castrista su inspiración, su gran referente político y cultural su obra literaria estuvo sometida al servicio de la "bondad" de su causa política; en su horizonte de migraña, el comunismo iba a ser "una aspirina del tamaño del sol", como escribió Dalton. Fue un fenómeno latinoamericano: el Departamento de América del Partido Comunista de Cuba pontificaba en lo político y la Casa de las Américas en lo cultural. Algunos escritores -Cortázar quizá sea el ejemplo que primero se me viene a la mente-apoyaban este contubernio desde la comodidad de las grandes capitales, pero hubo quienes lo vivieron apostando la vida, en especial en pequeños países aplastado por la bota militar como El Salvador. Los escritores de la generación que nos precedía fueron, pues, entusiastas y audaces peones cubanos. Con semejante herencia, ¿qué podía esperarse de nosotros? (24)

Esta generación del posboom (Shaw 1999), asumió, por un lado, un papel reactivo,

\footnotetext{
${ }_{15}$ Nacido en Holanda en 1931 y fallecido en 1988
} ISSN 0034-9631 (Impreso)

Vol. LXXIX, Núms. 244-245, Julio-Diciembre 2013, 951-968 ISSN 2154-4794 (Electrónico) de un cariz tan parricida como el de los propios escritores del boom llevaron a cabo con la generación que los precedió, en especial, los de la "novela de la tierra". Por otro lado, la reacción se orientó hacia los regímenes políticos autoritarios que pudieran imponer una única ideología. En ambos casos, la apuesta era por el pluralismo, la heterogeneidad, la heterodoxia y contra la "novela totalizadora". En suma, disenso y subversión de los grandes relatos explicativos de la condición humana. O hastío ante tanto exceso.

\subsection{El perdedor se hace mártir}

Esta categoría del perdedor resignado pero que procura la redención mediante un acto de arrojo que no hace más que reforzar su naturaleza perdedora es atribuible al personaje central de la novela La maravillosa vida breve de Óscar Wao de Junot Díaz (Santo Domingo, 1968). La voz de un narrador principal ("el Observador") sostiene el abanico de relatos que se tejen mediante la irreverencia y el humor. La novela de Junot Díaz plantea otros asuntos que van más allá de nuestro tema, pero que merecen por lo menos mencionarse. La novela ha sido escrita inicialmente en inglés, aunque un inglés que singulariza a los dominicanos afincados en Estados Unidos, más precisamente en Nueva Jersey. La procedencia de un escritor, es decir, su nacionalidad, su tradición son puestas en tela de juicio en la obra y abren en consecuencia un interrogante sobre cómo definir hoy la literatura latinoamericana en tiempos de la globalización. Con todo, y pese a estos desplazamientos territoriales y culturales, Junot Díaz no abandona los mitos de su cultura materna, como por ejemplo el fukú, un recurso caribeño, que consiste en una maldición lanzada contra aquellos que se odia, que se adhiere al maldecido al margen del tiempo y el espacio, lo único que importa es que produzca el efecto para el cual fue arrojado, es decir la destrucción. El fukú es intemporal, transgeográfico y plurigeneracional:

Dicen que primero vino de África, en los gritos de los esclavos; que fue la perdición de los taínos, apenas un susurro mientras un mundo se extinguía y otro despuntaba; que fue un demonio que irrumpió en la Creación a través del portal de pesadillas que se abrió en las Antillas. Fukú americanus, mejor conocido como fukú -en términos generales, una maldición o condena de algún tipo: en particular, la Maldición y Condena del Nuevo Mundo. (15)

El fukú aparece con la llegada de los europeos y "desde ese momento todo se ha vuelto una tremenda cagada" (15). Esta apelación a lo maravilloso para dar cuenta de los padecimientos tanto nacionales como individuales conecta la novela con el realismo mágico, sin embargo ello tiene efectos aparentes, puesto que la idea de que lo mágico puede ser una causa eficiente se disuelve en el humor que envuelve el conjunto de relato. Si el fukú es reconocido e incorporado lo es como un tributo a una tan abigarrada

Revista Iberoamericana, Vol. LXXIX, Núms. 244-245, Julio-Diciembre 2013, 951-968 ISSN 0034-9631 (Impreso) ISSN 2154-4794 (Electrónico) 
como caótica cultura como la caribeña. Con todo, el pensamiento mágico diluido en el humor contribuye a encontrar respuestas sobre la historia más reciente de la República Dominicana, ya que la maldición mayor procede del dictador Trujillo: o como lo llama el narrador: "Nuestro Dictador de Una Vez y Para Siempre, Rafael Leónidas Trujillo Molina". (16). Novela polifónica y de despliegue en diferentes direcciones espaciales y temporales trazan un abanico que va de lo individual a lo social, de un territorio imperia (Estados Unidos) a otro colonial (República Dominicana, invadida en 1965: "Santo Domingo fue Irak antes de que Irak fuera Irak", dice el narrador (18)), de la historia privada a la historia política. En este último caso la novela se convierte en históricopolítica mediante la denuncia de las atrocidades acometidas por el régimen de Trujillo, por medio de un recurso singular: la información histórica fluye en un rico aparato de notas a pie de página. Lo macro (el régimen de Trujillo y su maldición), lo micro (los efectos en las vidas de una familia caída en desgracia) y la responsabilidad del desafío a toda esa complejidad cae en Óscar Cabral: un joven gordo, feo, fanático de la cultura nerd, de una timidez enfermiza y esperanzado en convertirse en el Tolkien dominicano.

Desde el título La maravillosa vida breve de Óscar Wao encontramos ya elementos paródicos: Óscar Wao no es sino el remedo de Oscar Wilde y de "maravillosa" su vida no tiene nada. Estos recursos humorísticos no ocultan, sin embargo, ciertos elementos trágicos en la vida de Óscar Cabral, la principal será la brevedad de su vida, es decir muere siendo un joven. Su condición de perdedor no sólo se manifiesta en su aspecto físico, que ahuyenta toda cercanía femenina, y por tanto el encuentro del amor, sino principalmente en el hecho de que pertenece a una diáspora que lo transforma en un desarraigado e inadaptado dominicano en Nueva Jersey. Con todo, este personaje que despierta la risa compasiva es quien de manera novelesca le dará un último y digno sentido a su vida cambiándola por la muerte. En el gesto simple de pretender el amor de una prostituta dominicana, que a su vez es la amante de un capitán de la policía de estirpe trujillana, Óscar Cabral justifique el sonido onomatopéyico de admiración con el que lo han rebautizado: wao. No es para menos ya que su contrincante no es cualquier policía:

El capitán. Un jabao cuarentón, flaco, de pie junto a un jeep rojo impecable, bien vestido, con pantalones deportivos y una bien planchada camisa blanca, los zapatos brillantes como escarabajos. Uno de esos tipos altos, arrogantes, mordazmente guapos que hacen a la mayor parte del planeta sentirse inferior. También uno de esos hombre muy malos que ni siquiera el postmodernismo puede explicar. Había sido joven durante el trujillato, así que nunca tuvo la oportunidad de ejercer verdadero poder y no fue hasta la invasión norteamericana que alcanzó sus galones. Al igual que mi papá, apoyó a los invasores estadounidenses, y como era metódico y no demostró ni una gota de misericordia hacia los izquierdistas, ascendió - más bien, se abalanzó-a los rangos superiores de la policía militar. Estuvo muy ocupado bajo el Demonio Balaguer. Disparándoles a los sindicalistas desde el asiento trasero de los carros. Quemando casas de organizadores. Destrozándoles las caras a la gente a palancazos. (272) ISSN 0034-9631 (Impreso)

Vol. LXXIX, Núms. 244-245, Julio-Diciembre 2013, 951-968 ISSN 2154-4794 (Electrónico)
Este es el sujeto contra el que Óscar Cabral encontrará la manera más digna de perder: por amor, es decir, desinteresadamente como actúan los héroes de los comics que tanto admira. A la postre Óscar es una especie de Quijote que ha perdido el juicio no al extremo del personaje cervantino, pero sí el sentido sobre la realidad al ignorar los peligros que su vida corría y si en algún momento de lucidez lo percibe, en verdad no le importa. Por eso el modo como muere lo hace aparecer como un mártir. Curiosamente otra víctima tardía de Trujillo, desde el plano político, pero la víctima justa, exacta desde el punto de vista del fukú, es decir la maldición trujillana. Con lo cual se cierra todo un extenso círculo que abarca tanto a los individuos como Óscar Cabral o a la diáspora dominicana en general.

\section{Algunas Conclusiones}

Hemos tratado de demostrar algunas variaciones que ha experimentado el personaje en la novela hispanoamericana, especialmente desde los años 1970 más o menos la actualidad. Hemos coincidido con los tratadistas en el hecho de que la épica es inconcebible no solamente porque el género hace mucho tiempo que está agotado. Entre la heroicidad de la novela del Boom y la galería de personajes de la narrativa más reciente se interponen gravísimos episodios de la vida política latinoamericana, como las dictaduras de los años 1980 y las guerras centroamericanas. Sin que existan relaciones directas e inmediatas hemos sostenido que la declinación del héroe es posible asociarla con la declinación de las utopías y los grandes relatos. Las "respuestas" artísticas a estas encrucijadas fueron o la novela de denuncia o el testimonio. Sin embargo las novelas que nos han interesado poseen un nivel mayor de resolución del conflicto instaurado entre la realidad pasada y el vehículo de expresión. En efecto, haber centrado la problemática en el personaje que padece la derrota constituye un acierto estético, a nuestro modo de ver, que posibilita la elaboración no ya de una memoria hostil (que puede haberla desde luego) sino una memoria que no se desentiende del error, del desacierto o la creencia fantasmagórica de que toda teoría política es enteramente realizable. “¿Adónde pertenezco, entonces? -se pregunta Castellanos Moya frente a cómo definir su identidad- ¿Cuál es el cimiento de mi identidad como hombre y como escritor? La única respuesta que se me ocurre es esta: la memoria" ("Breves palabras impúdicas"). Leonardo Padura, Horacio Castellanos Moya, Junot Díaz, desde perspectivas diferentes que van del neopolicial, la imprecación o el humor construyen diversas respuestas para los episodios traumáticos de sus respectivas historias nacionales. 


\section{BiBLIOGRAFÍA}

Aguilar, Gonzalo. "Los intelectuales de la literatura: cambio social y narrativas de identidad". Historia de los intelectuales en América Latina. Carlos Altamirano (director). II. Los avatares de la "ciudad letrada" en el siglo XX. Buenos Aires: Katz, 2010.

Annino, Antonio y François-Xavier Guerra. Inventando la nación: Iberoamérica siglo $X I X$. México: Fondo de Cultura Económica, 2003.

Amar Sánchez, Ana María. Instrucciones para la derrota. Narrativas éticas y políticas de perdedores. Barcelona: Anthropos, 2010.

Arciniegas, Germán. "El siglo XIX en América y la deshumanización del héroe". América, Tierra Firme y otros ensayos. Prólogo Pedro Gómez Valderrama, Cronología y bibliografía Juan Gustavo Cobo Borda. Caracas: Biblioteca Ayacucho, 1990

Bajtín, Mijail. Teoría y estética de la novela: trabajos de investigación. Helena S. Kriúkova y Vicente Cazcarra, trads. Madrid: Taurus, 1989.

Bauzá, Hugo Francisco. El mito del héroe: morfología y semántica de la figura heroica. Buenos Aires: Fondo de Cultura Económica, 2007.

Calandra, Benedetta. "La Ford Foundation y la "Guerra Fría Cultural”. AMERICANÍA I (enero 2011).

Carpentier, Alejo. "Papel social del novelista". Literatura y arte nuevo en Cuba. Barcelona: Estela, 1971.

Castellanos Moya, Horacio. El asco: Thomas Bernhard en San Salvador. Barcelona: Tusquests, 2007.

Breves palabras impúdicas. Un ensayo y cuatro conferencias. San Salvador: Colección Revuelta, 2010.

"El escritor y la herencia". Cuadernos Hispanoamericanos 725 (2010).

Cortez, Beatriz. Estética del cinismo: pasióny desencanto en la literatura centroamericana de posguerra. Guatemala: F\&G Editores, 2010.

Crímenes, cadáveres, y cultura: siguiendo las pistas de la novela negra. Revista Iberoamericana LXXVI/231 (abril-junio 2010).

Díaz, Junot. La maravillosa vida breve de Óscar Wao. Achy Obejas, trad. Barcelona: Mondadori, 2008

Enzensberger, Hans Magnus. El perdedor radical: ensayo sobre los hombres del terror. Buenos Aires: Editorial La Página, 2009.

Eyzaguirre, Luis B. El héroe en la novela hispanoamericana del siglo XX. Santiago de Chile: Editorial Universitaria, 1973

Fontaine, Arturo. La vida doble. Buenos Aires: Tusquets Editores, 2010.

Franco, Jean. Decadencia y caída de la ciudad letrada: la literatura latinoamericana durante la guerra fría. Barcelona: Editorial Debate, 2003.

Revista Iberoamericana, Vol. LXXIX, Núms. 244-245, Julio-Diciembre 2013, 951-968 ISSN 0034-9631 (Impreso) ISSN 2154-4794 (Electrónico)
"Narrador, autor, superestrella: la narrativa latinoamericana en la época de la cultura de masas". Revista Iberoamericana XLVII/114-115 (julio-diciembre 1981): 129-48.

Franken K, Clemens A. "Leonardo Padura Fuentes y su detective nostálgico". Revista Chilena de Literatura 74 (abril 2009): 29-56.

Freud, Sigmund. Duelo y melancolía. Obras Completas. Tomo XIV. Buenos Aires: Amorrortu Editores, 2003.

Fuentes, Carlos. La nueva novela hispanoamericana. México: Cuadernos de Joaquín Mortiz, 1969.

Valiente Mundo Nuevo. Épica, utopía y mito en la novela hispanoamericana. México: Fondo de Cultura Económica, 1990.

Los 68. París, Praga, México. Barcelona: Debate, 2005.

Klahn, Norma y Wilfredo Corral. Los novelistas como críticos. México: Fondo de Cultura Económica, 1991.

Lingüistica y Literatura. Número monográfico dedicado a la novela policial colombiana 55 (enero-julio 2009): 1-169.

Ludmer, Josefina. "Tonos antinacionales en América Latina". Grumo 04 (octubre 2005).

Lukacs, Georg. El alma y las formas. Teoría de la novela. Manuel Sacristán, trad. México: Grijalbo, 1975

Maessenner, Rita de. "El canibalismo líquido de Junot Díaz". Contratiempo (marzo 2011): 89-97.

Martín Escribá, Àlex y Javier Sánchez Zapatero. "Una mirada al neopolicial latinoamericano: Mempo Giardinelli, Leonardo Padura y Paco Ignacio Taibo II". Anales de Literatura Hispanoamericana 36 (2007): 49-58.

Menjínar Ochoa, Rafael. Tiempos de locura. El Salvador 1979-1981. San Salvador: FLACSO, 2006

Padura, Leonardo. El hombre que amaba a los perros. Barcelona: Tusquets, 2010.

Pedrosa, José Manuel. “¿La muerte de la épica? Las metamorfosis de un género literario, entre la modernidad y la posmodernidad”. Revista de poética medieval 14 (2005) 47-94.

Pellicer, Rosa. "Críticos detectives y críticos asesinos. La busca del manuscrito en la novela policíaca hispanoamericana (1990-2006)". Anales de Literatura Hispanoamericana 36 (2007): 19-35.

Rodríguez-Luis, Julio. El enfoque documental en la narrativa hispanoamericana. Estudio taxonómico. México: Fondo de Cultura Económica, 1997.

Shaw, Donald. Nueva narrativa hispanoamericana: boom, posboom, posmodernismo. Madrid: Cátedra, 1999.

Skármeta, Antonio. "Al fin y al cabo es su propia vida la cosa más cercana que cada escritor tiene para echar mano". Más allá del Boom: literatura y mercado. Ángel Rama, et al. Buenos Aires: Folios Ediciones, 1984.

Revista Iberoamericana, Vol. LXXIX, Núms. 244-245, Julio-Diciembre 2013, 951-968 ISSN 0034-9631 (Impreso) ISSN 2154-4794 (Electrónico) 
Stonor Saunders, Frances. La CIA y la guerra fría cultural. Rafael Fontes, trad. Barcelona: Editorial Debate, 2001.

Zambrano, María. "El sentido de la derrota". Bohemia (La Habana, año 45, 25 de octubre de 1953). 